\title{
Evaluation of Strength Properties of In-Service X80 Pipeline Steel Using Small Punch Test and Backpropagation Neural Network
}

\section{Ming Song ( $\nabla$ songmingx@gmail.com )}

UPC: China University of Petroleum Huadong https://orcid.org/0000-0003-0693-3832

\section{Xuyang Li}

China University of Petroleum East China - Dongying Campus: China University of Petroleum Huadong

\section{Wenchun Jiang}

China University of Petroleum East China - Dongying Campus: China University of Petroleum Huadong Jiru Zhong

East China University of Science and Technology

\section{Kaishu Guan}

East China University of Science and Technology

\section{Original Article}

Keywords: True stress-strain curve, Small punch test, Backpropagation neural network, Hollomon formula, Finite element method

Posted Date: January 9th, 2021

DOl: https://doi.org/10.21203/rs.3.rs-141384/v1

License: (1) This work is licensed under a Creative Commons Attribution 4.0 International License. Read Full License 


\section{Title page}

\section{Evaluation of Strength Properties of In-Service X80 Pipeline Steel Using Small Punch Test and Backpropagation Neural Network}

Ming Song, born in 1984, is currently an assistant professor at Department of Engineering Mechanics, China University of Petroleum (East China) China. He received his Ph.D. degree from East China University of Science and technology, China, in 2013. His research interests include structural integrity of pressure vessels and pipelines.

Tel: +86 18562821169; E-mail: songmingx@gmail.com

Xuyang Li, born in 1996, is currently a master candidate at College of Pipeline and Civil Engineering, China University of Petroleum (East China), China

E-mail: 704821886@qq.com

Wenchun Jiang, born in 1980, is currently a full professor at China University of Petroluem (East China) China.

E-mail: jiangwenchun@126.com

Jiru Zhong, born in 1988, is currently a postdoctoral researcher at East China University of Science and technology, China.

E-mail: zhongjiru@outlook.com

Kaishu Guan, born in 1968, is currently a full professor at East China University of Science and technology, China. His research interests include structural integrity of pressure vessels and pipes and miniature specimen tests.

Tel: +86 13166213046; E-mail: guankaishu@ecust.edu.cn

Corresponding author: Ming Song, E-mail: songmingx@gmail.com 
ORIGINAL ARTICLE

\section{Evaluation of Strength Properties of In-Service X80 Pipeline Steel Using}

\section{Small Punch Test and Backpropagation Neural Network}

Ming Song ${ }^{1, a}$, Xuyang $\mathrm{Li}^{1}$, Wenchun Jiang ${ }^{2}$, Jiru Zhong ${ }^{3}$, Kaishu Guan ${ }^{3}$

${ }^{1}$ College of Pipeline and Civil Engineering, China University of Petroleum (East China), Qingdao 266580, China

${ }^{2}$ College of New Energy, China University of Petroleum (East China), Qingdao 266580, China

${ }^{3}$ School of Mechanical and Power Engineering, East China University of Science and Technology,

Shanghai 200237, China

\section{a songmingx@gmail.com}

Keywords: True stress-strain curve, Small punch test, Backpropagation neural network, Hollomon formula, Finite element method 
Abstract. Evaluating the strength properties of materials of an in-service pipeline without shutting down transportation has been always a challenge. A novel and non-destructive method for determining the true stress-strain curve of pipeline steel based on backpropagation artificial neural network and small punch test is proposed in this study. The elastoplastic mechanical properties of the pipeline steels could be obtained by this method. The load-displacement curves of 2261 groups of different hypothetical materials were obtained by the finite element model of small punch test within Gurson-Tvergaard-Needleman (GTN) damage parameters and used to train the neural network. The relationship between the loaddisplacement curve of small punch test and the true stress-strain curve of the conventional uniaxial tensile test was established based on the trained neural network. The accuracy and wide applicability of the trained neural network were verified by the experimental data of four types of materials obtained by small punch test and standard tensile test, respectively. The established relationship can be used to predict the true stress-strain curve of the pipeline steels to determine the elastoplastic mechanical properties only by the load-displacement curve of the small punch test without performing the conventional tensile test.

\section{Introduction}

Small punch test (SPT) [1-4] is one of these nearly non-destructive methods for miniaturized specimen techniques. It has been applied for the evaluation of a wide range of mechanical properties, including strength, ductility, fracture toughness, ductile-brittle transition temperature and high temperature mechanical behavior, i.e. creep. Mao correlated the yield load and the maximum load of the SPT with the yield strengths and the ultimate tensile strength of various kinds of materials, and gave the corresponding empirical formula [5]. Chica analyzed the initial stage of the load-displacement curve of the SPT, correlated the slope of the initial stage with the elastic modulus of alloys, and obtained the empirical formula between them [6]. Based on the principle of equivalent energy, Peng [7] analyzed the 
third stage of load-displacement curve of SPT, and the true stress-strain curve and ultimate tensile strength of the materials were obtained. Baik et al. [8] tested the temper-embrittled $\mathrm{Ni}-\mathrm{Cr}$ steel and defined the area under the load-displacement curve as the fracture energy of the SPT, and founded the correlation between the Charpy V-notch test results and the SPT, then the ductile-brittle transition temperature (DBTT) was determined. Hurst [9] proposed a $J$-integral estimation method for annular notched small punch specimens of P91 martensitic steel based on fracture energy. The local analysis and simulation of $J-R$ bending line and fracture toughness $J_{I C}$ were carried out by using SPT. The empirical correlation method was used by the most of researchers to obtain the correlation formula of material strength and fracture toughness based on their own test results. However, due to a wide variety of differences of the nature of material used in the test, the configuration of the testing machine, and the definition methods of yield load on the load-displacement curve of SPT, the empirical formulas proposed by different researchers are also different [10-16]. These empirical formulas are not comparable to each other, resulting in the consumption of research efforts and research resources. Therefore, it is urgent to find a more reasonable and effective method to correlate the small punch test with the conventional standard tests, and then the accurate elastic-plastic mechanical properties of materials would be extracted.

In this study, a method was proposed to obtain the true stress-strain curve of metallic materials through SPT and backpropagation (BP) neural network [17-19], which is an algorithm of artificial neural network and is widely used in the training of feedforward neural networks for supervised learning. The complete elastoplastic mechanical properties of materials could be obtained by this method. The load-displacement curves of SPTs were obtained by the finite element model of SPT with Gurson-Tvergaard-Needleman (GTN) damage parameters. The BP neural network was trained with the load-displacement curves and true stress-strain curves, and the relationship between them was established. The load-displacement curve of X80 pipeline steel obtained by SPT was input to BP neural network, and the true stress-strain curve of X80 pipeline steel was obtained, thus the yield strength and ultimate tensile strength of X80 pipeline steel 
were also determined. Compared with the conventional empirical correlation method, this method has the advantages of low cost, accuracy and high efficiency.

\section{Experiment and finite element modeling}

The chemical composition of X80 pipeline steel used in the test was shown in Table 1 . The engineering stress-strain curve of virgin X80 pipeline steel was obtained by conventional uniaxial tensile test and the strain distribution of fractured tensile specimen was measured by digital image correlation (DIC) method. Three groups of tests were carried out and average values of the load and displacement were used to plot the curve. The strain distribution of fractured tensile specimen and engineering stress-strain curves of X80 pipeline steel was shown in Fig. 1. The elastic modulus $E$, yield strength $\sigma_{\mathrm{y}}$ and ultimate tensile strength of X80 pipeline steel were $206 \mathrm{GPa}, 594 \mathrm{MPa}$ and $713 \mathrm{MPa}$, respectively.

(a)

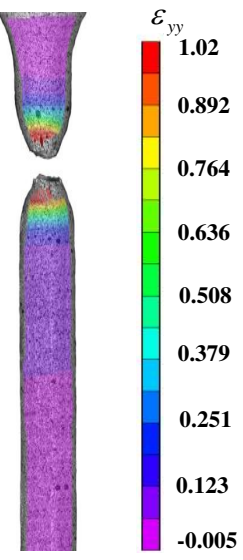

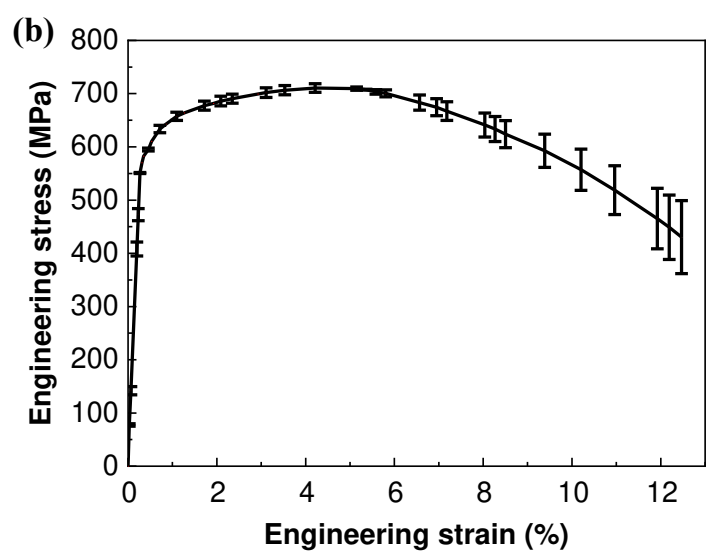

Fig. 1 (a) Strain distribution on specimen surface, and (b) Engineering stress-strain curve of X80 pipeline steel obtained by uniaxial tensile test

The plastic parameters of X80 pipeline steel required for numerical simulation were obtained from the true stress-strain curve. Hollomon formula were used to describe the elastoplastic constitutive relations of most ductile materials as follows,

$$
\sigma= \begin{cases}E \varepsilon & \sigma>\sigma_{y} \\ K \varepsilon^{n} & \sigma<\sigma_{y}\end{cases}
$$

where $\sigma$ is true stress, $\sigma_{\mathrm{y}}$ is yield strength, $\varepsilon$ is true strain, $E$ is elastic modulus, $K$ is strength coefficient 
and $n$ is strain hardening index. The true stress and true strain of materials can be calculated by Eq. (2) and Eq. (3).

$$
\begin{aligned}
& \sigma=\sigma_{\mathrm{E}}\left(1+\varepsilon_{\mathrm{E}}\right) \\
& \varepsilon=\ln \left(1+\varepsilon_{\mathrm{E}}\right)
\end{aligned}
$$

where $\sigma_{\mathrm{E}}$ is engineering stress and $\varepsilon_{\mathrm{E}}$ is engineering strain. The true stress-strain curve of material is shown in Fig. 2, the part of the curve between yield strength and ultimate tensile strength was fitted by power function, and the parameters $K$ and $n$ in Hollomon formula were obtained.

Table 1 Chemical composition of X80 pipeline steel (wt. \%)

\begin{tabular}{ccccccccccccr}
\hline $\mathrm{C}$ & $\mathrm{Si}$ & $\mathrm{Mn}$ & $\mathrm{P}$ & $\mathrm{S}$ & $\mathrm{Cr}$ & $\mathrm{Mo}$ & $\mathrm{Ni}$ & $\mathrm{Nb}$ & $\mathrm{V}$ & $\mathrm{Ti}$ & $\mathrm{Cu}$ & $\mathrm{Fe}$ \\
\hline 0.043 & 0.23 & 1.87 & 0.01 & 0.0028 & 0.025 & 0.27 & 0.23 & 0.06 & 0.006 & 0.017 & 0.13 & Bal. \\
\hline
\end{tabular}

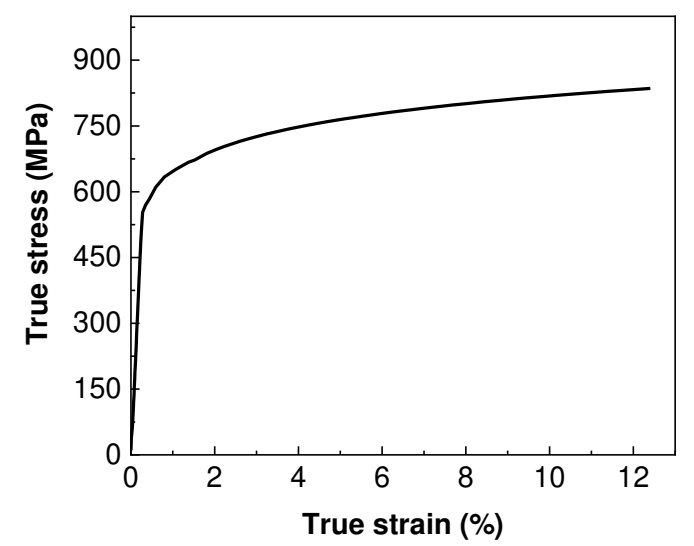

Fig. 2 True stress-strain curve of X80 pipeline steel

In addition, the relationship between engineering stress and real stress-strain can be obtained by deducing the above formulas, which can be expressed as follows:

$$
\sigma_{\mathrm{E}}=\sigma e^{-n}
$$

where the $e=2.718$ is a natural constant. When the engineering stress reaches the maximum value, i.e. $\sigma_{\mathrm{b}}$, the ultimate strain $\varepsilon_{\mathrm{E}}$ equals the strain hardening index $n$ [21], so the ultimate tensile strength can be given as follows [22],

$$
\sigma_{\mathrm{b}}=K\left(\frac{n}{e}\right)^{n}
$$


from the above relationship, it can be seen that the ultimate tensile strength of different materials can be deduced from the corresponding Hollomon formula. The SPT device was shown in Fig. 3 (a). The punch head was hemispherical, the radius $r$ was $1.25 \mathrm{~mm}$ and the lower die diameter $D$ was $4 \mathrm{~mm}$, with $0.5 \mathrm{~mm}$ chamfer edge. The thickness $t$ and diameter $d$ of SPT specimen were $0.5 \mathrm{~mm}$ and $10 \mathrm{~mm}$, respectively. The specimen was placed on the lower die and pressed by the upper die to prevent sliding. During the test, the punch was loaded downward at a constant rate of $0.2 \mathrm{~mm} / \mathrm{min}$. The center of the specimen was pressed down until the specimen breaks. The load and the displacement of the punch were recorded during the whole test process, and the load-displacement curve of the SPT was obtained, as shown in Fig. 4 (b). The whole curve can be divided into five parts: I. Elastic stage; II. Transition stage from elasticity to plasticity; III. Strengthening stage; IV. Geometric softening and failure stage; V. Fracture stage of specimen. The load-displacement curves of the SPT can be used to obtain the parameters that characterize the elastoplastic behavior of the material, such as the initial slope $e_{\text {ini }}$ of the first stage, yield load $F_{\mathrm{P}}$ and maximum load $F_{\max }$, as shown in Fig. 3 (b).

(a)

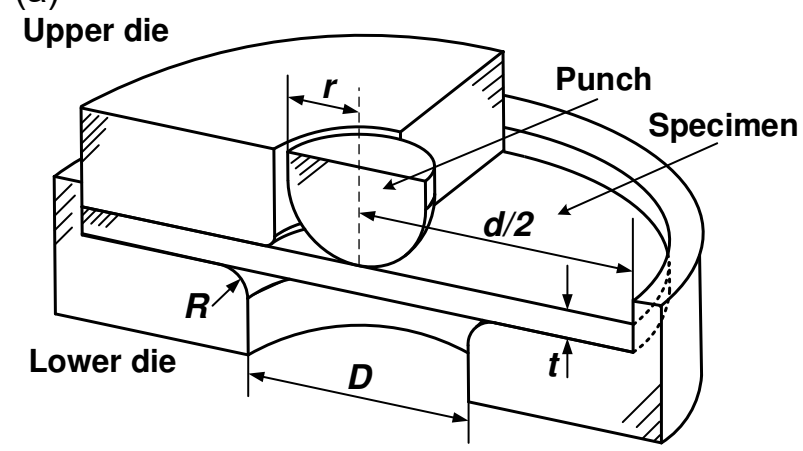

(b) 200

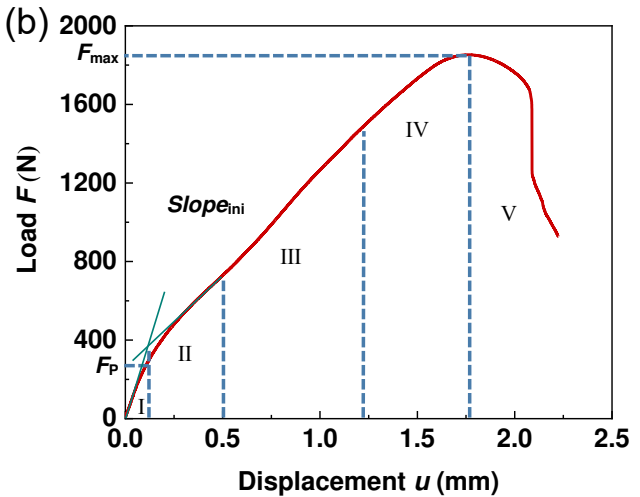

Fig. 3 (a) Schematic of the SPT device, and (b) load-displacement curve of SPT

These parameters were closely related to the elastic modulus $E$, yield strength $\sigma_{\mathrm{y}}$ and ultimate tensile strength $\sigma_{\mathrm{b}}$ obtained by uniaxial tensile test. Mao [5] conducted SPT and uniaxial tensile tests on various materials, and correlated the test results. The empirical formulas for obtaining mechanical properties of materials were obtained as follows: 


$$
\begin{gathered}
E=\alpha \cdot \frac{\text { slope }_{\mathrm{ini}}}{t} \\
\sigma_{\mathrm{y}}=\beta \cdot \frac{F_{\mathrm{P}}}{t^{2}} \\
\sigma_{\mathrm{b}}=\gamma_{1} \cdot \frac{F_{\mathrm{max}}}{t^{2}}+\gamma_{2}
\end{gathered}
$$

where the $t$ is the initial thickness of the small punch specimen, $\alpha, \beta, \lambda_{1}$, and $\lambda_{2}$ are the correlation coefficients, which are equal to $17.47,0.36,0.13$ and -0.32 respectively. The elastic modulus $E=225 \mathrm{GPa}$, yield strength $\sigma_{\mathrm{y}}=473 \mathrm{MPa}$ and ultimate tensile strength $\sigma_{\mathrm{b}}=982 \mathrm{MPa}$ were obtained by substituting the parameters obtained from the test results of SPT of X80 pipeline steel. Compared with the uniaxial tensile test results, the errors were $9.2 \%, 20.3 \%$ and $37.8 \%$ respectively. It can be found that the mechanical properties of X80 pipeline steel can be obtained directly from empirical formulas given by other researcher, but the errors were larger than the standard conventional test. In order to obtain more accurate mechanical properties such as elastic modulus, yield strength and ultimate tensile strength of pipeline steel materials by SPT, it was necessary to conduct SPT and uniaxial tension test for a variety of pipeline steel materials to fit new empirical formulas. However, if the in-service pipeline is inspected without shutting down transportation, the samples required for standard test cannot be taken out. Therefore, it is necessary to develop a new test method to obtain the mechanical properties of in-service pipeline materials under the condition of ensuring the integrity of pipeline. Martin et al. [23-24] obtained fracture parameters of tough materials by combining neural network with SPT, which has high accuracy. It showed that the combination of neural network and SPT was suitable for testing mechanical properties of materials. Therefore, in this study, BP neural network combined with SPT was used to obtain the elastoplastic mechanical properties parameters of in-service pipeline materials.

The finite element software ABAQUS was used to simulate the SPT process. The SPT specimen was a circular axisymmetric structure. Therefore, Fig 4 shows the 2D axisymmetric finite element model of 
SPT specimen. The punch, upper die and lower die were considered as rigid body without considering the deformation of them. The upper die and lower die were fixed in all degrees of freedom, whereas the punch can be moved vertically by a displacement boundary condition. The contact between the specimen and punch, upper die and lower die was modeled, and the friction coefficient $\mu$ was 0.15 . Four-node quadratic reduction integral element CAX4R was selected for the element. Ten layers of meshes are divided in thickness direction.

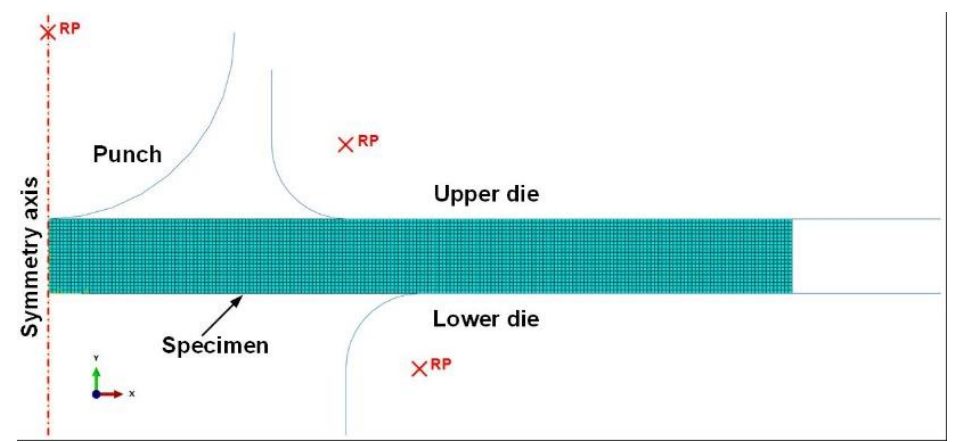

Fig. 4 Axisymmetric finite element model of SPT

In order to simulate the elastoplastic deformation, damage and fracture behavior of SPT specimens, the definition of material parameters was divided into two parts: (1) the definition of material elastoplastic parameters; (2) the definition of material damage parameters. The elastoplastic parameters required in the finite element model include elastic modulus, Poisson's ratio and stress-strain relationship, which can be obtained by uniaxial tensile test.

For material damage parameters, the GTN damage model is adopted and its yield function is expressed as follows [25],

$$
\Phi=\left(\frac{\sigma_{e q}}{\sigma_{\mathrm{y}}}\right)^{2}+2 q_{1} f^{*} \cosh \left(-\frac{3}{2} \frac{q_{2} \sigma_{H}}{\sigma_{\mathrm{y}}}\right)-\left(1+q_{3} f^{*^{2}}\right)=0
$$

where $\sigma_{e q}$ represents the macroscopic effective Von Mises stress, $\sigma_{\mathrm{y}}$ denotes the yield strength of matrix 
material, $\sigma_{H}$ is the macro hydrostatic stress, $f^{*}, q_{1}, q_{2}$ and $q_{3}$ are the material damage parameters. Through numerical analysis, the commonly used values of damage parameters given by Tvergaard [26] are $q_{1}=1.5, q_{2}=1, q_{3}=q_{1}^{2} \circ f^{*}$ is defined as:

$$
f^{*}= \begin{cases}f & f \leq f_{c} \\ f_{c}+\frac{f_{F}^{*}-f_{c}}{f_{F}-f_{c}}\left(f-f_{c}\right) & f_{c}<f<f_{F} \\ f_{F}^{*} & f \geq f_{F}\end{cases}
$$

where $f$ denotes the current void volume fraction; $f_{F}$ and $f_{c}$ define the void volume fraction at failure and at a critical situation where $f$ starts to deviate from $f^{*}$, respectively; $f_{F}^{*}$ is the $f^{*}$ value at fracture. The porosity in GTN model consists of two parts: (1) the volume fraction increases with the increase of existing voids; (2) new voids are generated in materials due to the large plastic strain. Therefore, if straincontrolled nucleation is considered, the increase of porosity can be written as follows:

$$
\&=\underset{\text { growth }}{\&}+\underset{\text { nucl }}{\&}=(1-f) \underset{\mathrm{g}_{k}}{\&}+\frac{f_{N}}{s_{N} \sqrt{2 \pi}} \exp \left[-\frac{1}{2}\left(\frac{\varepsilon_{m}^{p}-\varepsilon_{n}}{s}\right)^{2}\right] \underset{m}{g_{m}}
$$

where the growth of existing porosity $f_{\text {growth }}^{\&}$ is controlled by plastic strain, while the nucleation of new voids $\underset{n u c l}{\&}$ depends on (1) the average strain $\varepsilon_{n}$ during nucleation; (2) the volume fraction of nucleable voids $f_{N} ;(3)$ the standard deviation $s_{N}$ of the average strain $\varepsilon_{n}$ during nucleation; (4) the initial void volume fraction $f_{0} . \quad \varepsilon_{m}^{p}$ and $g_{m}^{2}$ are equivalent plastic strain and its rate of change respectively.

\section{Results and disscussions}

\subsection{Experimental results and continuous damage model}

In the finite element model of SPT, the void parameters $f_{0}, f_{\mathrm{N}}, f_{\mathrm{c}}$ and $f_{\mathrm{F}}$ of X80 pipeline steel are unknown, so the values of these parameters should be determined. The specimens with diameter of $10.0 \mathrm{~mm}$ and thickness of $0.600 \mathrm{~mm}$ were cut from the pipeline by wire cutting. Sandpaper was used to grind the 
specimens to remove the influence areas of overheating and work hardening, so that there were no cracks and other macro defects in the specimens. In order to ensure the accuracy of the test, three groups of tests were prepared. The final specimen thickness $t$ was $0.495 \mathrm{~mm}, 0.498 \mathrm{~mm}$ and $0.499 \mathrm{~mm}$, respectively. The load-displacement data of each specimen were recorded and three groups of load-displacement curves of SPT were obtained. The finite element model of multi-group SPT were simulated to ensure that the plastic parameters of the material were unchanged, and only the GTN damage parameters were changed, Finally, compare the simulation results with the test results. Fig. 5 shows the curve with the highest matching degree with test. In this paper, the GTN damage parameters are finally determined as shown in Table 2.

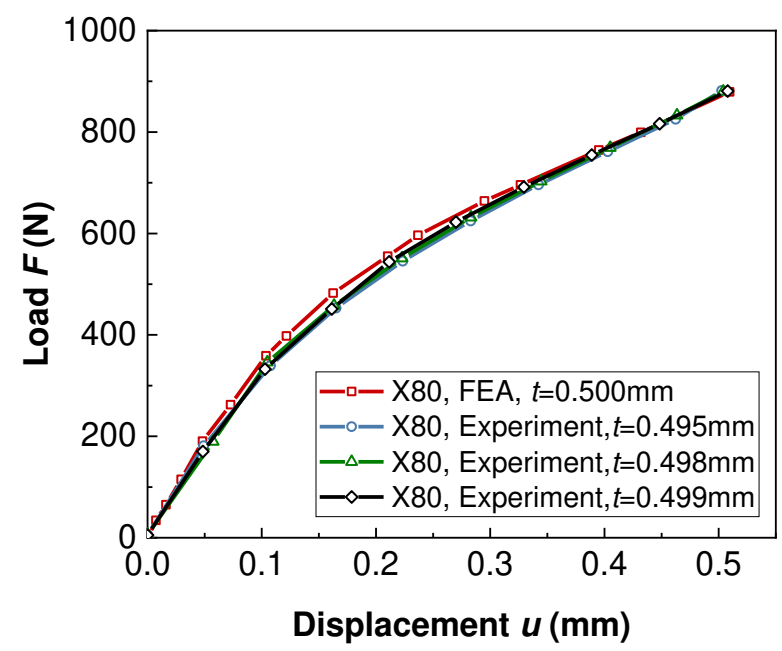

Fig. 5 Comparisons of stages I and II between experimental and simulation results of SPT

Table 2 Material parameters of GTN model for X80 pipeline steel

\begin{tabular}{ccccccccc}
\hline$q_{1}$ & $q_{2}$ & $q_{3}$ & $\varepsilon_{N}$ & $s_{N}$ & $f_{0}$ & $f_{\mathrm{N}}$ & $f_{\mathrm{c}}$ & $f_{F}$ \\
\hline 1.5 & 1 & 2.25 & 0.3 & 0.1 & 0.0025 & 0.0008 & 0.03 & 0.15 \\
\hline
\end{tabular}

\subsection{BP neural network modeling}

BP neural network can train a lot of data and establish corresponding relationship between two different factors. In this paper, the load-displacement curve of SPT was taken as input set and the true stress-strain curve as output set. The main training scheme of BP neural network is shown in Fig. 6. 

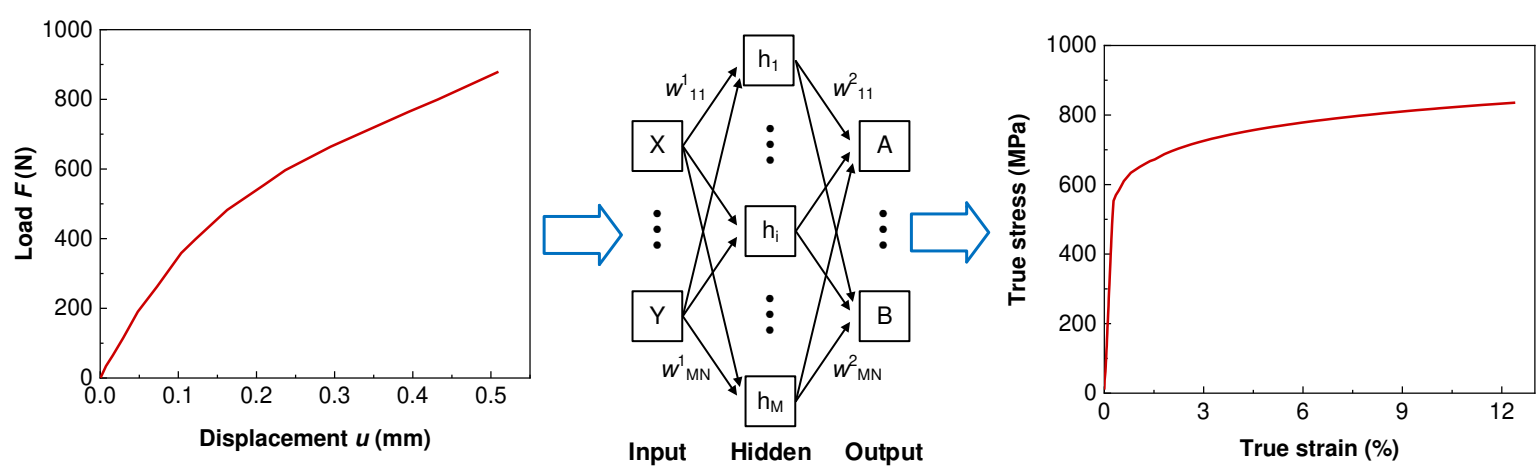

Fig. 6 Schematic of BP neural network training

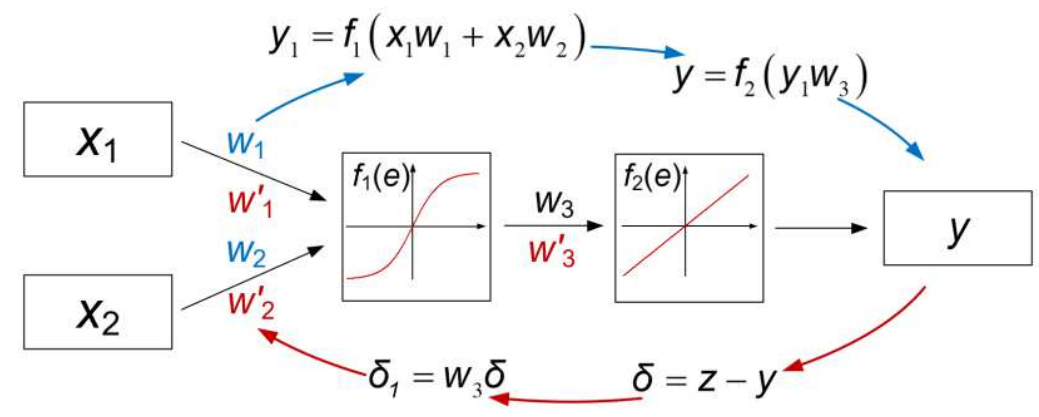

Fig. 7 Computational principle of BP neural network

In the training process of BP neural network, a large number of data need to be calculated to reduce the error continuously. Fig. 7 shows the calculation process, it is divided into two steps: (1) Firstly, the target error value was set, and a group of load-displacement data and real stress-strain data of SPT of the same material were input. After receiving a set of load-displacement data of the SPT, the activation function $f_{1}(\mathrm{e})$ calculated these data in this layer., and the calculated result $y_{1}$ was output to the second layer neurons. The output set $y$ was calculated by the second layer neurons, and the error $\delta$ between the result and the input true stress-strain data was obtained; (2) The calculated error $\delta$ was fed back to the layers of neurons, and the weight value of each layer of neurons were corrected by formula (9), (10), (11) respectively, and the corrected weight value was used to repeat step (1) until the error was less than the preset target error.

$$
w_{1}^{\prime}=w_{1}+\eta \delta_{1} \frac{d f_{1}(e)}{d e} x_{1}
$$




$$
\begin{aligned}
& w_{2}^{\prime}=w_{2}+\eta \delta_{1} \frac{d f_{1}(e)}{d e} x_{2} \\
& w_{3}^{\prime}=w_{3}+\eta \delta \frac{d f_{2}(e)}{d e} y_{1}
\end{aligned}
$$

where $w$ is weight value, $\eta$ is the learning rate, $f(e)$ is the activation function and $\delta$ is the calculation error.

\subsection{Assembling the data base}

The training set of BP neural network includes two parts: the load-displacement curve of SPT as input set and the true stress-strain curve of the same material as output set. The true stress-strain curve can be obtained by systematically changing the parameters $K$ and $n$ in Hollomon formula. In order to obtain more accurate training results, the accuracy and comprehensiveness of training set data should be guaranteed. Therefore, the database should contain most of the true stress-strain curves of common metals. The strain hardening index $n$ of most materials ranges from 0.005 to 0.6 , and the strength coefficient $K$ ranges from $200 \mathrm{MPa}$ to $2000 \mathrm{MPa}$. However, when parameter $K$ becomes small, with the decrease of $n$ value, the true stress corresponding to the true strain of 0.002 , i.e. the yield strength of material becomes very small, and the yield strength ratio of material becomes very small, while this kind of metal is very rare, so this kind of true stress-strain curve can be deleted to improve the accuracy of the training results of BP neural network. Finally, the range of parameters $K$ and $n$ is determined as shown in Table 3.

Table 3 Range of parameter $K$ and $n$

\begin{tabular}{cccc}
\hline Parameter & Minimum & Minimum & Number \\
\hline$K$ & 200 & 2000 & 19 \\
$n$ & 0.01 & 0.6 & 119 \\
\hline
\end{tabular}

A new true stress-strain curve can be obtained by changing the parameters $K$ and $n$. Each true stress- 
strain curve was substituted into the finite element model of the SPT to obtain the complete loaddisplacement curve.

When BP neural network determines input data, each column matrix is identified as a set of input data, so each curve corresponds to a column of data. The load-displacement curve of SPT and the true stressstrain curve of material are composed of data points, and each data point is confirmed by abscissa and ordinate coordinates. Therefore, each data point on the curve needs to be transformed in the way shown in Table 4. Load-displacement curve of SPT is expressed by $\left(X_{i, j}, Y_{i, j}\right)$, true stress-strain curve is expressed by $\left(A_{m . n}, B_{m . n}\right)$. Each load-displacement curve takes 20 sets of coordinates, and the true stress-strain curve takes 8 set of coordinates. $\left(X_{1}, Y_{1}\right),\left(X_{2}, Y_{2}\right), \ldots,\left(X_{20}, Y_{20}\right)$ is transformed into $\left[X_{1}, X_{2}, \ldots, X_{20}, Y_{1}\right.$, $\left.Y_{2}, \ldots Y_{120}\right]$, the transformation mode of material true stress-strain curve is the same as that of loaddisplacement curve. The database structure of training set of BP neural network is shown in Table 4.

Table 4 Database structure of training set of BP neural network

\begin{tabular}{ccc}
\hline Sample number & Input set & Output set \\
\hline 1 & $X_{1,1}, \ldots, X_{20,1}, Y_{1,1}, \ldots, Y_{20,1}$ & $A_{1,1}, \ldots, A_{8,1}, B_{1,1}, \ldots, B_{8,1}$ \\
2 & $X_{1,2}, \ldots, X_{20,2}, Y_{1,2}, \ldots, Y_{20,2}$ & $A_{1,2}, \ldots, A_{8,2}, B_{1,2}, \ldots, B_{8,2}$ \\
$\vdots$ & $\vdots$ & $\vdots$ \\
2261 & $X_{1,2261} \ldots, X_{20,2261}, Y_{1,2261}, \ldots, Y_{20,2261}$ & $A_{1,2261}, \ldots, A_{20,2261}, B_{1,2261}, \ldots, B_{8,2261}$ \\
\hline
\end{tabular}

\subsection{Calculation results of BP neural network}

The load-displacement curve of X80 pipeline steel obtained from SPT was input into the trained BP neural network to obtain its true stress-strain curve. Compared with the uniaxial tensile test results, as shown in Fig. 8, the matching degree between the calculated results of BP neural network and uniaxial tensile test was higher. 


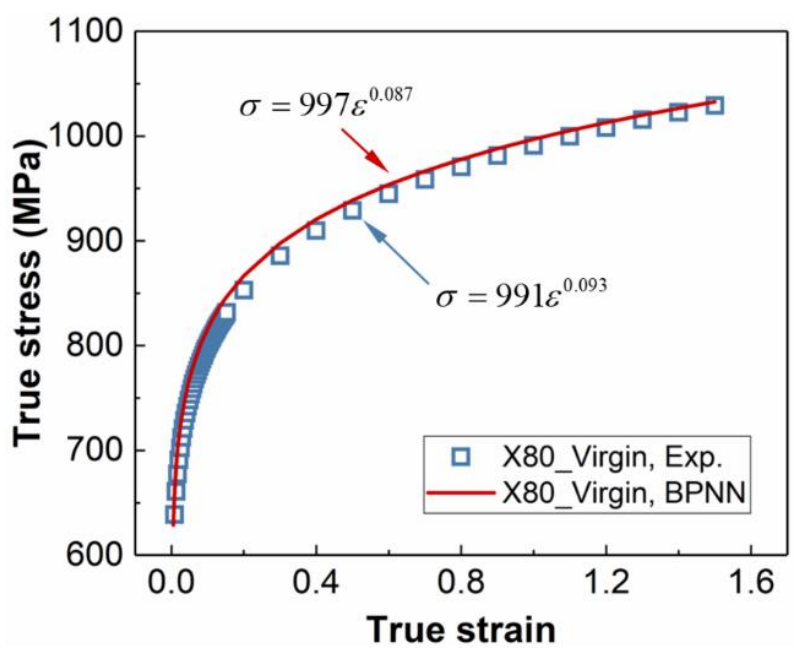

Fig. 8 Comparison of true stress-strain curves obtained by BP neural network and uniaxial tensile test.

The true stress-strain curves obtained by experiment and BP neural network were processed. The parameters $K$ and $n$ in Hollomon formula were obtained by fitting curve. The ultimate tensile strength was obtained by Eq. (5). When the true strain is 0.002 , the stress is taken as the yield strength of the material. The uniaxial tensile test results and the results calculated by BP neural network were listed in Table 5.

In order to further verify the accuracy of the calculation results of the BPNN, load-displacement data of AISI 304L, P92 and DP600 of SPT in references [7] and [27] are plotted in Fig. 9 and substituted into the trained BPNN to obtain the corresponding true stress-strain curves, which were compared with the uniaxial tensile test results given by other researchers as Fig. 9 Shown. 


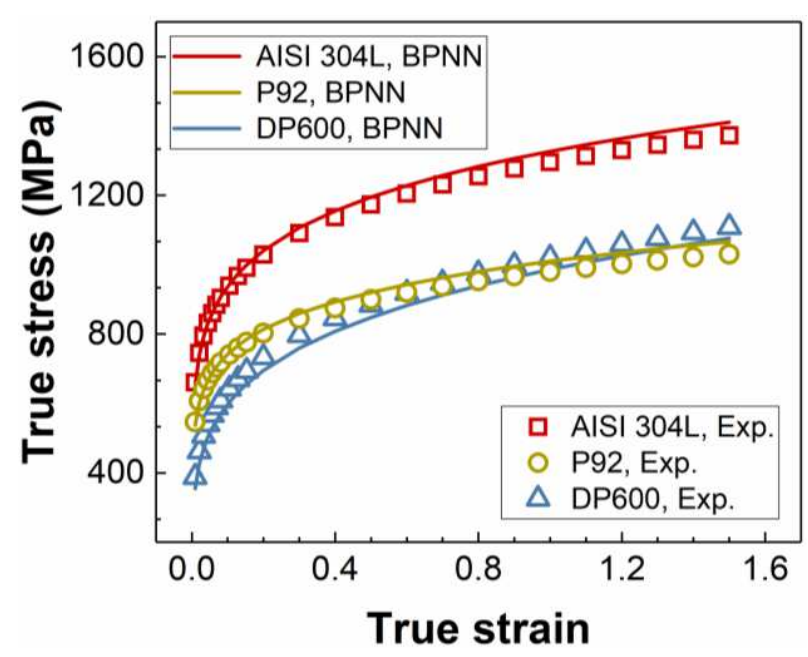

Fig. 9 Comparison of true stress-strain curves of materials in reference obtained between BP neural network and uniaxial tensile tests

Table 5 The mechanical properties of materials obtained by BP neural network and uniaxial tensile test

\begin{tabular}{|c|c|c|c|c|c|c|}
\hline Material & $\begin{array}{c}\text { Yield } \\
\text { strength } \\
R_{\mathrm{eL}}(\mathrm{MPa})\end{array}$ & $\begin{array}{c}\text { Yield } \\
\text { strength } \\
R_{\mathrm{eL}_{-} \mathrm{BPNN}} \\
(\mathrm{MPa})\end{array}$ & $\begin{array}{c}\text { Relative errors } \\
\left(R_{\mathrm{eL} \_\mathrm{BPNN}}-R_{\mathrm{eL}}\right) / R_{\mathrm{eL}}(\%)\end{array}$ & $\begin{array}{l}\text { Ultimate } \\
\text { tensile } \\
\text { strength } \\
R_{\mathrm{m}}(\mathrm{MPa})\end{array}$ & $\begin{array}{c}\text { Ultimate } \\
\text { tensile } \\
\text { strength } \\
R_{\mathrm{m} \_ \text {BPNN }} \\
(\mathrm{MPa})\end{array}$ & $\begin{array}{c}\text { Relative errors } \\
\left(R_{\mathrm{m} \_\mathrm{BPNN}}-R_{\mathrm{m}}\right) / R_{\mathrm{m}}(\%)\end{array}$ \\
\hline X80_virgin & 594 & 581 & -2.2 & 713 & 739 & 3.6 \\
\hline AISI 304L & 653 & 621 & -4.9 & 892 & 927 & 3.9 \\
\hline P92 & 613 & 578 & -5.7 & 875 & 831 & -5.0 \\
\hline DP600 & 261 & 256 & -1.9 & 540 & 518 & -4.1 \\
\hline
\end{tabular}

From the Table. 5, it can be seen that the maximum error of elastoplastic mechanical properties of X80 pipeline steel calculated by BP neural network is $9.3 \%$, compared with uniaxial tensile test results, which is much smaller than the error of $37.8 \%$ calculated by conventional empirical correlation method. The load-displacement curve of the material obtained from the SPT can be input into the trained BP neural network, and the true stress-strain curve can be obtained, and then the elastoplastic mechanical properties parameters of corresponding material can be obtained. 


\section{Conclusions}

In this study, a method was proposed to obtain the true stress-strain curve of metallic materials by using SPT, finite element method and BP neural network. Through developing the finite element model of SPT with GTN damage parameters, which was verified by the experimental results, load-displacement curves of different 2261 groups of hypothetical materials were obtained, combined with the corresponding true stress-strain curve, BP neural network was trained to establish the relationship between SPT and conventional uniaxial tensile test. By comparing the results of SPT and uniaxial tensile test of X80 pipeline steel and the test data of different types of materials in the references, the accuracy and wide applicability of this method were verified. The main conclusions can be drawn as follows.

(1) The load-displacement curves obtained by the finite element model of SPT with GTN damage parameters have a very good agreement with the experimental results for the X80 pipeline steel.

(2) The load-displacement curve of SPT of X80 pipeline steel is substituted into the trained BP neural network to obtain its true stress-strain curve. The calculated yield strength $\sigma_{\mathrm{y}_{\_} \mathrm{BPNN}}=581 \mathrm{MPa}$, ultimate tensile strength $\sigma_{\mathrm{b}_{-} \mathrm{BPNN}}=739 \mathrm{MPa}$. The error is $-2.2 \%$ and $3.6 \%$ respectively compared with uniaxial tensile test results.

(3) The developed BP neural network is used to calculate the mechanical properties of materials in the references. Compared with the uniaxial tensile test results, the maximum error is $-5.7 \%$, which is lower than that of the conventional empirical correlation method.

The results demonstrate that the true stress-strain curves and elastoplastic properties of metallic materials could be accurately obtained by the method combining SPT and artificial BP neural network without performing conventional tensile test. 


\section{Declaration}

\section{Acknowledgements}

The authors sincerely thanks to Professors Wen Qin and Jerzy A. Szpunar at University of Saskatchewan for their critical discussion and reading during manuscript preparation.

\section{Funding}

Supported by the National Natural Science Foundation of China (51805543), the Natural Science Foundation of Shandong Province of China (ZR2019MEE108, ZR2017BEE037), and the Fundamental Research Funds for the Central Universities (18CX05002A).

\section{Availability of data and materials}

The datasets supporting the conclusions of this article are included within the article.

\section{Authors' contributions}

The authors' contributions are as follows:

Xuyang Li was in charge of the experiment and data analysis;

Ming Song wrote the manuscript;

Wenchun Jiang was in charge of revising and modification of the manuscript;

Jiru Zhong assisted with sampling, laboratory analyses and discussion;

Kaishu Guan supervised the whole project and supplied ideas in the discussion.

\section{Competing interests}

The authors declare no competing financial interests. 


\section{Consent for publication}

Not applicable

\section{Ethics approval and consent to participate}

Not applicable

\section{References}

[1] M.P. Manahan, A.S. Argon, O.K. Harling, The development of a miniaturized disk bend test for the determination of postirradiation mechanical properties, Journal of Nuclear Materials. 104 (1981): 1545-1550.

[2] F.H. Huang, M.L. Hamilton, G.L. Wire, Bend testing for miniature disks, Nuclear Technology. 57.2 (1982): 234-242.

[3] A. Janča, J. Siegl, P. Haušild, Small punch test evaluation methods for material characterization, Journal of Nuclear Materials. 481 (2016): 201-213.

[4] P. Hähner, C. Soyarslan, B.G. Çakan, S. Bargmann, Determining tensile yield stresses from Small Punch tests: A numerical-based scheme, Materials \& Design. 182 (2019): 107974.

[5] X. Mao, H. Takahashi, Development of a further-miniaturized specimen of $3 \mathrm{~mm}$ diameter for tem disk ( $\Phi 3 \mathrm{~mm}$ ) small punch tests, Journal of Nuclear Materials. 150. 1 (1987): 42-52.

[6] J.C. Chica, P.M.B. Díez, M.P. Calzada, Improved correlation for elastic modulus prediction of metallic materials in the Small Punch Test, International Journal of Mechanical Sciences. 134 (2017): $112-122$.

[7] Y. Peng, L. Cai, H. Chen, C. Bao, A new method based on energy principle to predict uniaxial stress- 
strain relations of ductile materials by small punch testing, International Journal of Mechanical Sciences. 138 (2018): 244-249.

[8] J.M. Baik, O. Buck, J. Kameda, Small punch test evaluation of intergranular embrittlement of an alloy steel, Scripta Metallurgica. 17. 12 (1983): 1443-1447.

[9] R. Hurst, Y. Li, K. Turba, Determination of fracture toughness from the small punch test using circular notched specimens, Theoretical and Applied Fracture Mechanics. 103 (2019): 102238.

[10]J. Kameda, X. Mao, Small-punch and TEM-disc testing techniques and their application to characterization of radiation damage, Journal of Materials science. 27.4 (1992): 983-989.

[11]D. Finarelli, M. Roedig, F. Carsughi, Small punch tests on austenitic and martensitic steels irradiated in a spallation environment with $530 \mathrm{MeV}$ protons, Journal of nuclear materials. 328. 2-3 (2004): 146-150.

[12]Z.X. Wang, H.J. Shi, J. Lu, P. Shi, X.F. Ma, Small punch testing for assessing the fracture properties of the reactor vessel steel with different thicknesses, Nuclear engineering and design. 238. 12 (2008): 3186-3193.

[13]C. Rodríguez, J.G. Cabezas, E. Cárdenas, F.J. Belzunce, C. betegonó, Mechanical properties characterization of heat-affected zone using the small punch test, Welding Journal. 88 (2009): 188192.

[14]F. Dobeš, P. Dymáček, M. Besterci, Estimation of the mechanical properties of aluminium and an aluminium composite after equal channel angular pressing by means of the small punch test, Materials Science and Engineering: A. 26 (2015): 313-321.

[15]L. Xue, X. Ling, S. Yang, Mechanical behaviour and strain rate sensitivity analysis of TA2 by the small punch test, Theoretical and Applied Fracture Mechanics. 99 (2019): 9-17. 
[16]S. Holmström, I. Simonovski, D. Baraldi, M. Bruchhausena, E. Altstadtb, R. Delvillec, Developments in the estimation of tensile strength by small punch testing, Theoretical and Applied Fracture Mechanics. 101 (2019): 25-34.

[17]J. Li, D. Zhao, B.F. Ge, K.W. Yang, Y.W. Chen, A link prediction method for heterogeneous networks based on BP neural network, Physica A: Statistical Mechanics and its Applications. 495 (2018): 117.

[18]D. Zheng, Z. Qian, Y. Liu, C. Liu, Prediction and sensitivity analysis of long-term skid resistance of epoxy asphalt mixture based on GA-BP neural network, Construction and Building Materials. 158 (2018) 614-623.

[19]M. Liu, J. Shi, A cellular automata traffic flow model combined with a BP neural network based microscopic lane changing decision model, Journal of Intelligent Transportation Systems. 23. 4 (2019): 309-318.

[20]M.F. Moreno, G. Bertolino, A. Yawny, The significance of specimen displacement definition on the mechanical properties derived from Small Punch Test, Materials \& Design. 95 (2016): 623-631.

[21]J.Y. Kim, K.W. Lee, J.S. Lee, D. Kwon, Determination of tensile properties by instrumented indentation technique: Representative stress and strain approach, Surface and Coatings Technology. 201. 7 (2006): 4278-4283.

[22]J. Li, F. Li, X. Ma, Q. Wang, J. Dong, Z. Yuan, A strain-dependent ductile damage model and its application in the derivation of fracture toughness by micro-indentation, Materials \& Design. 67 (2015): 623-630.

[23]M Abendroth, M Kuna, Determination of deformation and failure properties of ductile materials by means of the small punch test and neural networks, computational materials Science. 28. 3-4 (2003) 
633-644.

[24]M. Abendroth, M. Kuna, Identification of ductile damage and fracture parameters from the small punch test using neural networks, Engineering fracture mechanics. 73.6 (2006): 710-725.

[25]A.L. Gurson, Continuum theory of ductile rupture by void nucleation and growth: Part I-Yield criteria and flow rules for porous ductile media, Journal of engineering materials and technology. 99. 1 (1977): 2-15.

[26]V. Tvergaard, Influence of voids on shear band instabilities under plane strain conditions, International Journal of fracture. 17.4 (1981): 389-407.

[27]M.F. Moreno, G. Bertolino, A. Yawny. The significance of specimen displacement definition on the mechanical properties derived from small punch test. Materials \& Design 95 (2016): 623-631. 
Figures

(a)
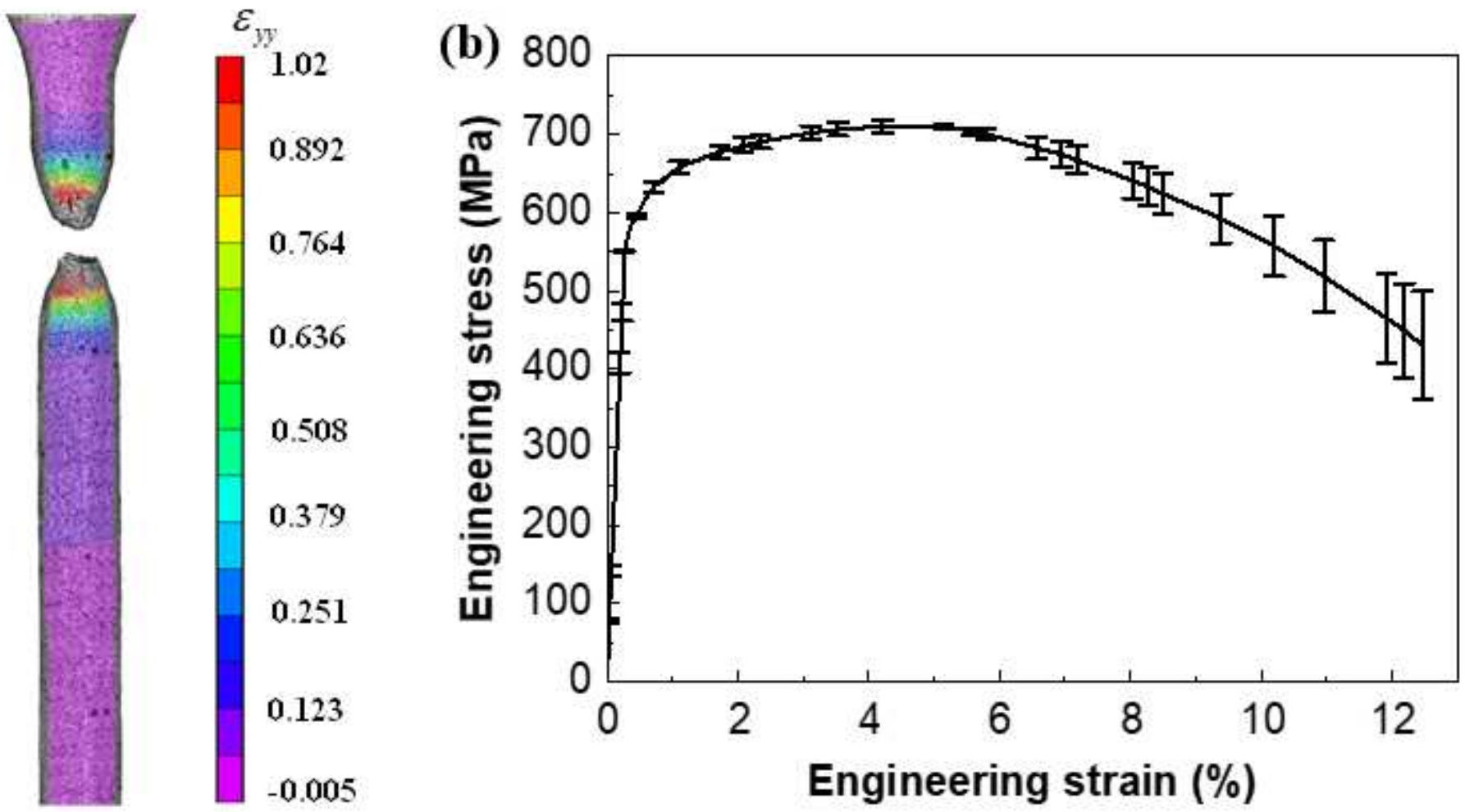

Figure 1

(a) Strain distribution on specimen surface, and (b) Engineering stress-strain curve of X80 pipeline steel obtained by uniaxial tensile test

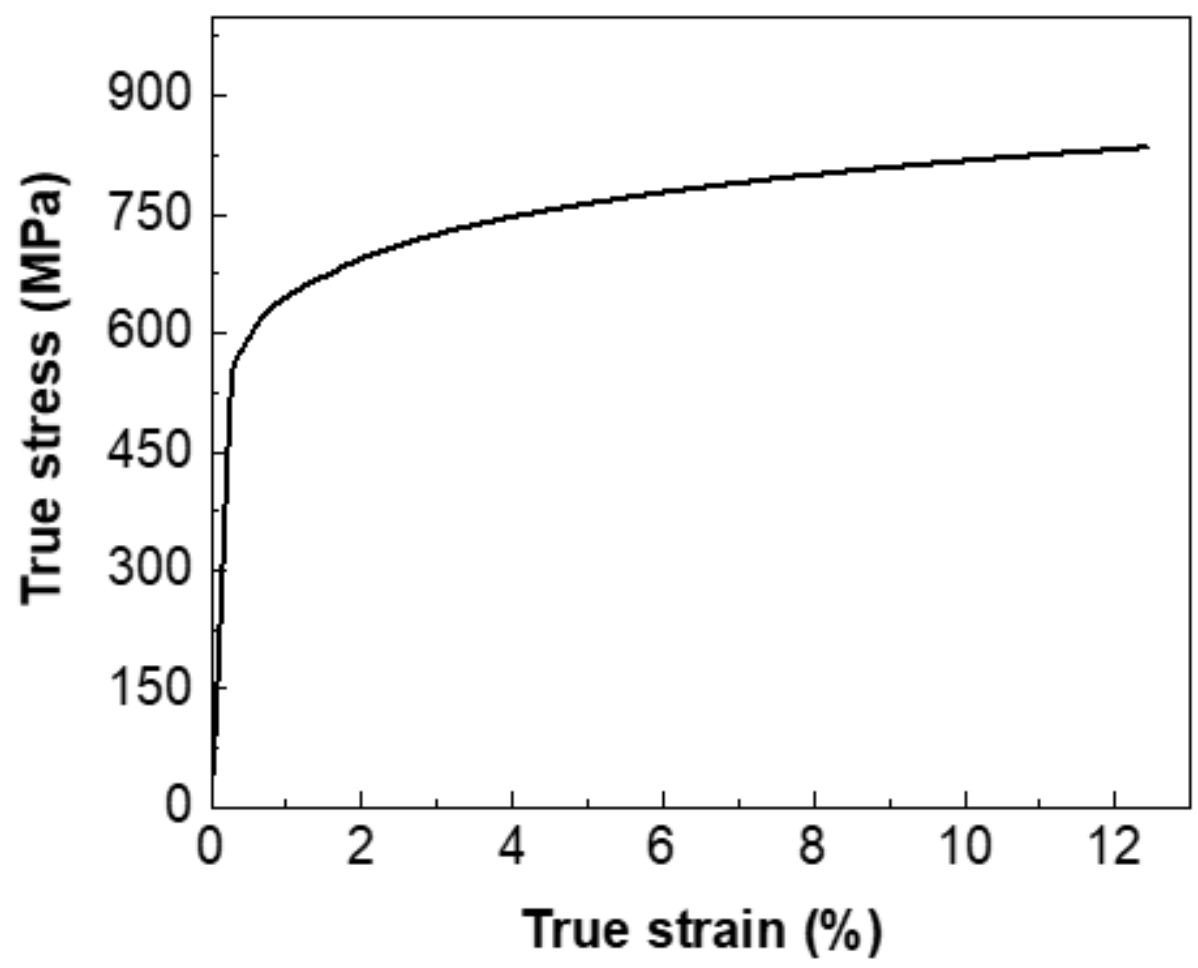


Figure 2

True stress-strain curve of $\mathrm{X} 80$ pipeline steel

(a)

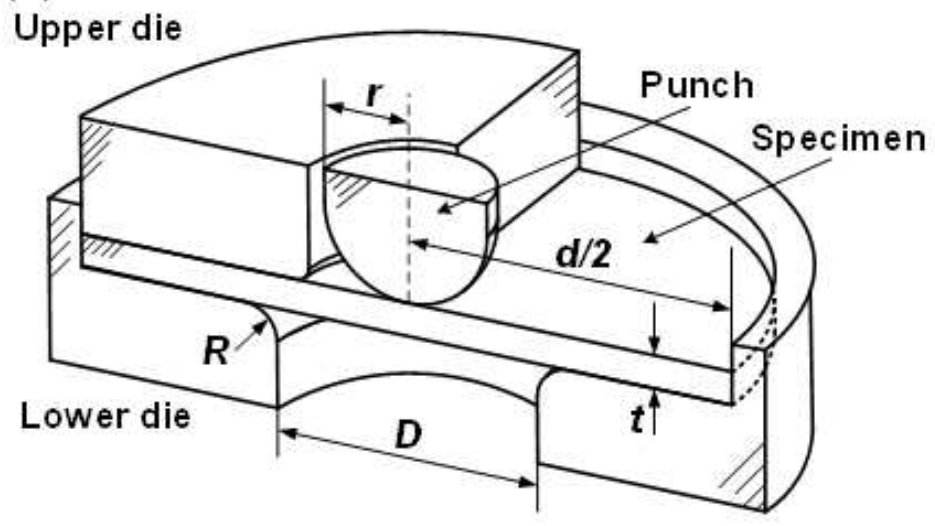

(b)

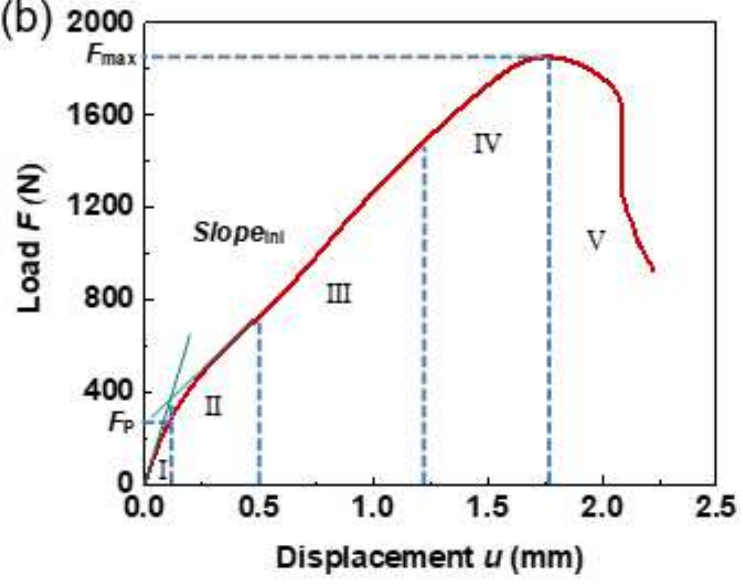

\section{Figure 3}

(a) Schematic of the SPT device, and (b) load-displacement curve of SPT

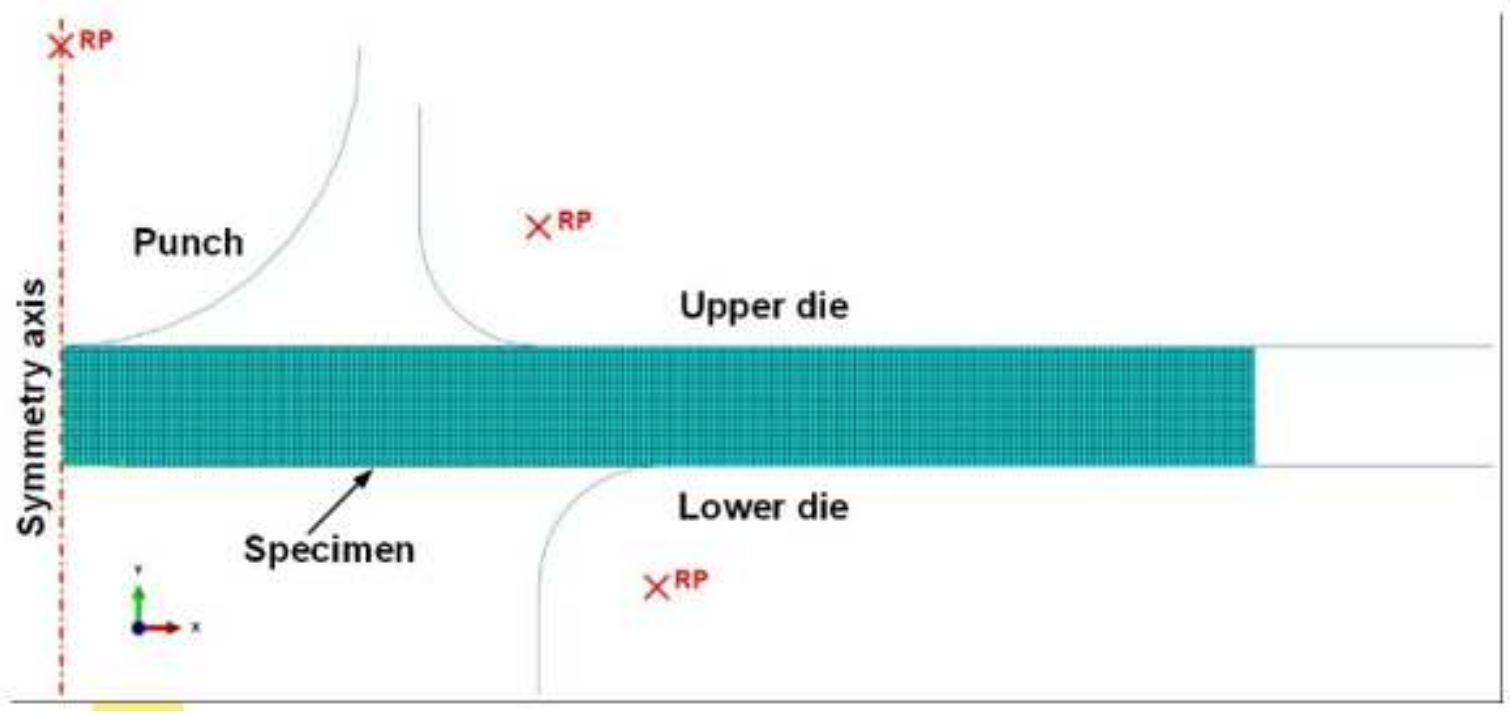

Figure 4

Axisymmetric finite element model of SPT 


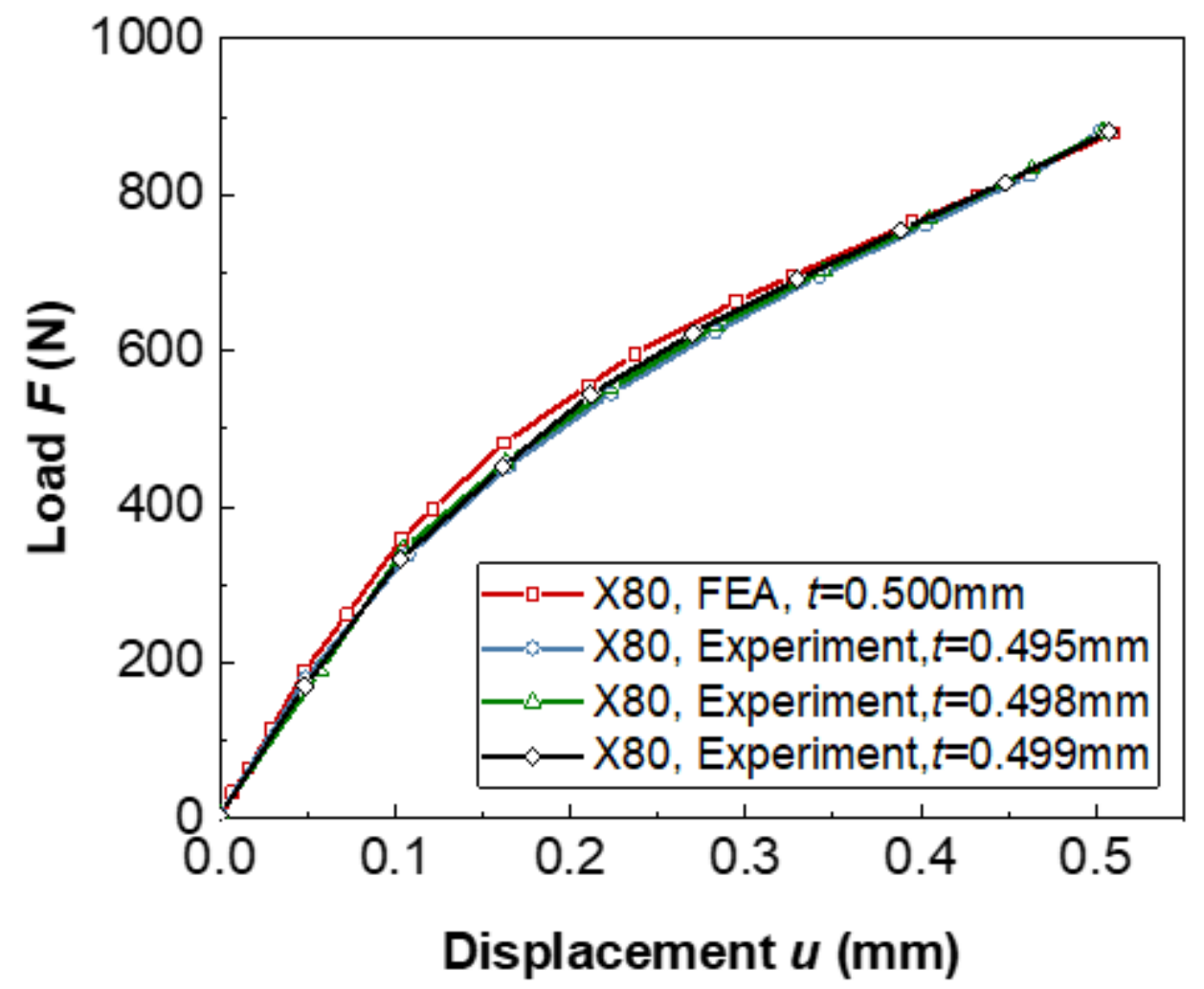

Figure 5

Comparisons of stages I and II between experimental and simulation results of SPT
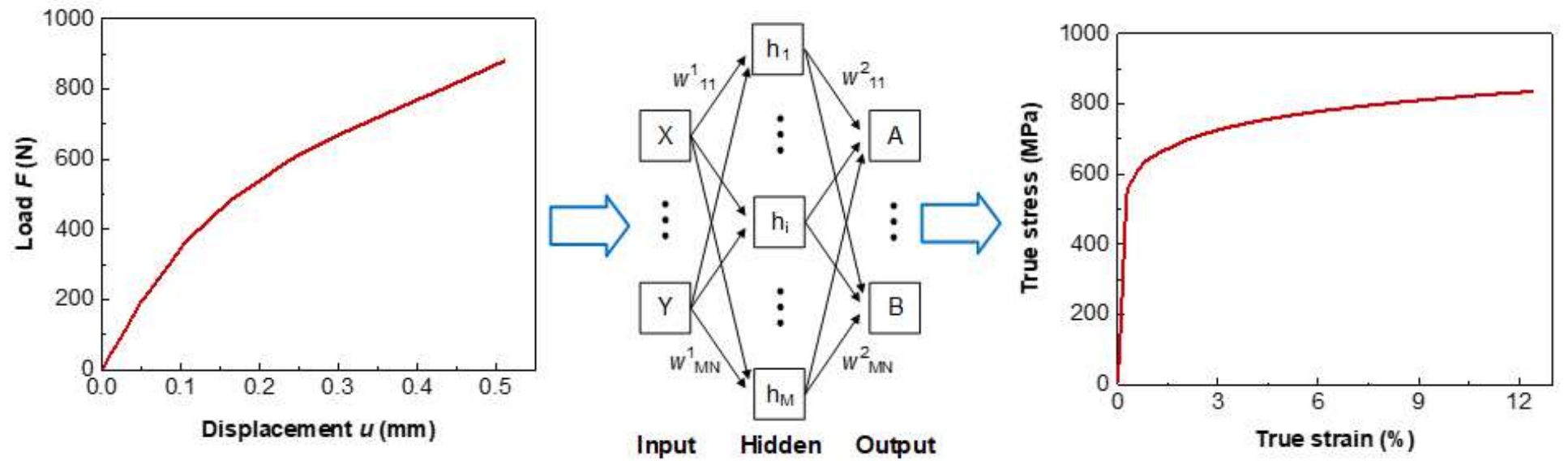

Figure 6

Schematic of BP neural network training 


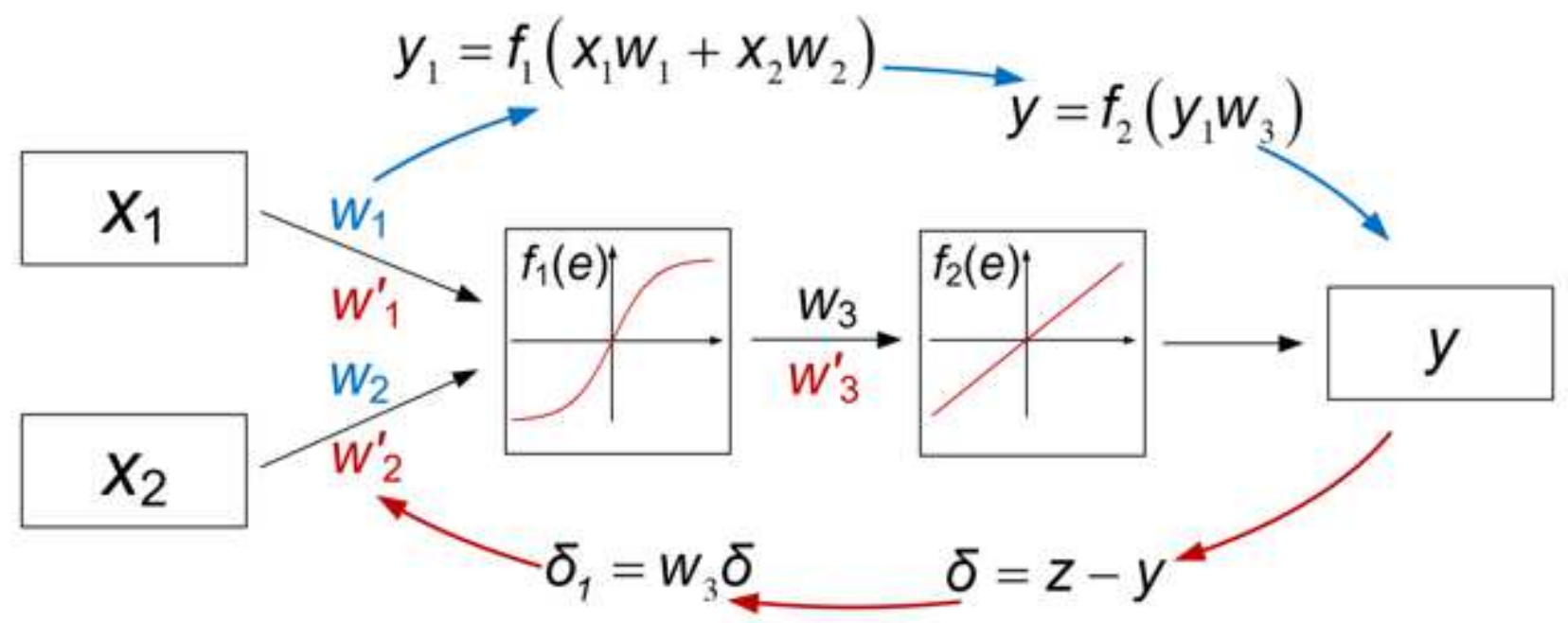

Figure 7

Computational principle of BP neural network

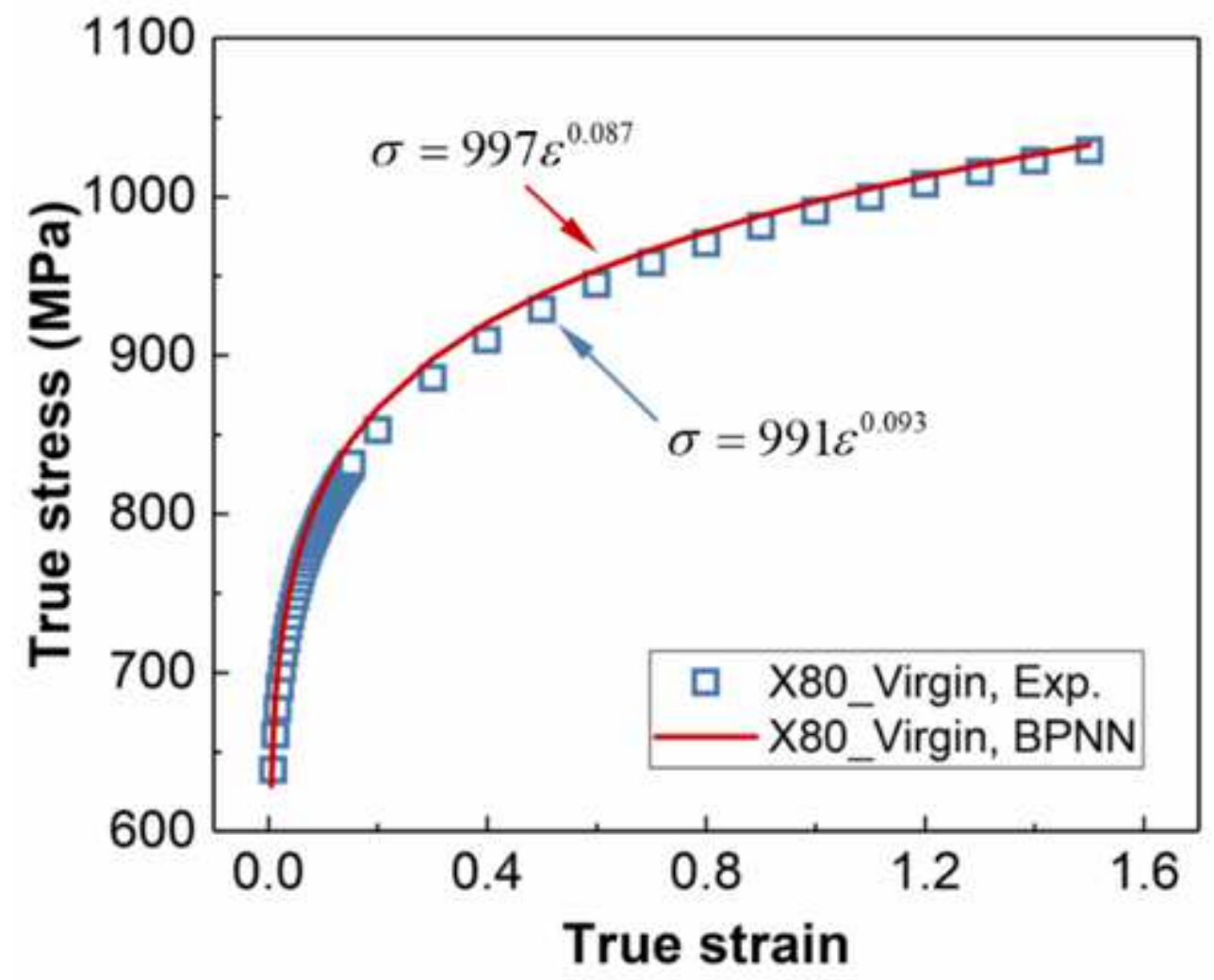

Figure 8

Comparison of true stress-strain curves obtained by BP neural network and uniaxial tensile test. 


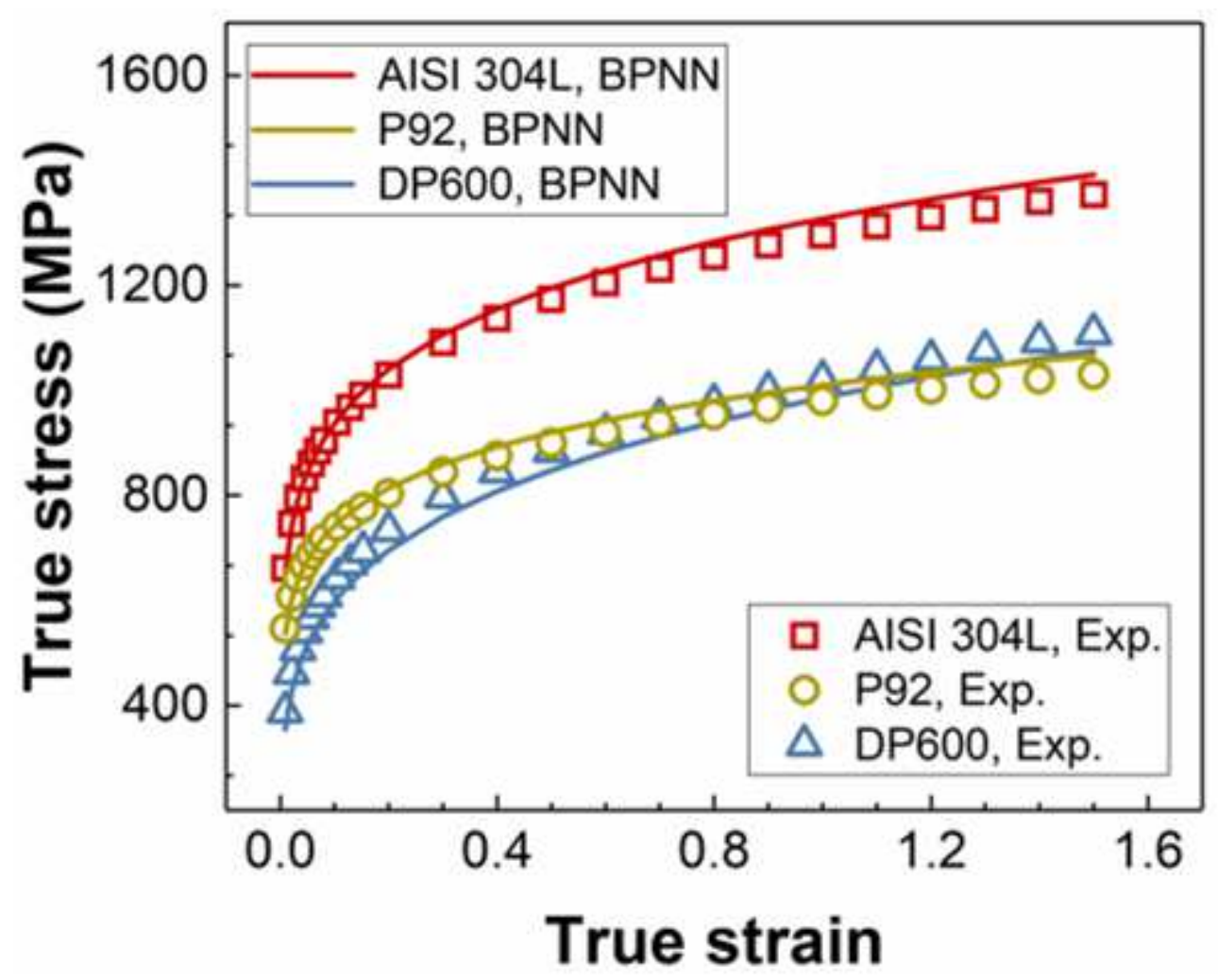

Figure 9

Comparison of true stress-strain curves of materials in reference obtained between BP neural network and uniaxial tensile tests 